Behavior and Social Issues, 18, 155-174 (2009). (C) Karola Dillenburger \& Lyn McKerr. Readers of this article may copy it without the copyright owner's permission, if the author and publisher are acknowledged in the copy and the copy is used for educational, not-for-profit purposes.

\title{
"40 Years Is An Awful Long Time": Parents Caring For Adult Sons ANd Daughters With Disabilities
}

\author{
Karola Dillenburger ${ }^{1}$ \\ Lyn McKerr \\ Queen's University of Belfast
}

\begin{abstract}
Older people who are caring for their adult sons and daughters with disabilities are under tremendous stress because they may suffer health problems themselves; have financial problems due a lifetime of caring; may have to care on their own due to the death of their spouse; worry about the future care of their child; and may feel uncomfortable approaching professionals for help. Professionals working with these families need to take contextual pressures into consideration when planning intervention. Twenty-nine parents of 27 adults with intellectual and/or developmental disabilities (including autism) were asked about present care and service arrangements, health issues, family support, and "futures planning." The research reported here identifies complex networks of relationships. Virtual absence of structured futures planning was one of the key issues. Recommendations are made for professionals working in this field.

KEYWORDS: older caregivers, adults with disabilities, future planning, behavior analysis
\end{abstract}

We must build a world free of unnecessary barriers, stereotypes, and discrimination.... policies must be developed, attitudes must be shaped, and buildings and organizations must be designed to ensure that everyone has a chance to get the education they need and live independently as full citizens in their communities. (Barack Obama, April 11, 2008).

The number of children diagnosed with disabilities and their life expectancy is increasing and together with an increase in parental age at birth this means that more people are carers well into their old age (Minnes \& Woodford, 2005). Most adults with learning disabilities (89\%) live in the community, mainly supported by unpaid members of their family (Robinson \& Williams, 2002). Statistics of

\footnotetext{
${ }^{1}$ This research was supported through a Changing Ageing Partnership (CAP) Research Seed Grant. The authors thank Liam McDermot, and Siobhan Owens for research assistance. Reprint requests should be addressed to Dr Karola Dillenburger, School of Education, Queen's University of Belfast, 69 University Street, Belfast BT71HL. Email: k.dillenburger@qub.ac.uk
} 
older people providing unpaid care for family members with disabilities make for grim reading. Over half of the unpaid carers are over 55 years of age; $25 \%$ of them are over the age of 70 years; many provide more than 50 hours of care per week. Nearly a quarter of the carers are not in good health themselves (Dahlberg, Demack, \& Bambra, 2007) and men are particularly over-represented in the 90+ age group. In the UK alone, Buckner and Yeandle (2007) estimated that unpaid carers save in excess of $£ 87$ billion for the economy, a sum that exceeds the total expenditure on the National Health Service (NHS).

Care arrangements are virtually unknown to service providers until there is a crisis. Family carers worry about the future but oftentimes postpone forward planning. "[M] any family carers do have serious misgivings about their relative leaving home... [due to]... dissatisfaction with the range and quality of care available, their belief that their relative does not want to leave, and their own inter-dependent relationship with their relative for companionship or practical or financial support" (Walker \& Walker, 1998). Consequently, the resettlement of adults with disabilities from their family home happens only after the serious illness or death of the main carer (Scott \& Donnelly, 2008).

Walker and Walker (1998) are cautious not to lay blame onto ageing family carers who are not planning ahead and advise that the behaviour of carers has to be viewed in context. The problem is rooted in traditional psychological approaches, which commonly relate age as the independent variable to developmental milestones as dependent variables (Gallagher \& Keenan, 2006). People are said to behave in certain ways because of their age or the stage of development they have reached. For example, according to Erikson's (1963) theory of psycho-social development, older adults have to master the developmental tasks of resolving the conflict between ego-integrity vs. despair by reviewing life accomplishments, dealing with loss, and preparing for their own death. According to this theory, older parent carers may be categorised as in despair, if they are not in a position to accomplish these tasks because they are still in the midst of caring for their "child" with disabilities. Consequently, this kind of theory leaves older carers at a loss and may lead to apportioning blame to the older person for not "solving the developmental task" appropriately.

A behaviour analytic perspective on aging prevents such labelling (Cambridge Centre for Behavioral Studies, 2009; Dillenburger \& Keenan, 1997). In behaviour analysis, environmental events are identified as independent variables, while behaviour (publicly observable, private, verbal, cognitive, and emotional) is regarded as the dependent variable in the analysis (Gallagher \& Keenan, 2006). The if-then relations between dependent variables and inde- 
PARENTS CARING FOR ADULT SONS AND DAUGHTERS

\begin{tabular}{|lll} 
Antecedent event \\
sets the occasion
\end{tabular}$\longrightarrow \begin{gathered}\text { Behavioural } \\
\text { repertoire is } \\
\text { emitted }\end{gathered} \longrightarrow \begin{gathered}\text { Consequent event } \\
\text { influences future } \\
\text { probability of } \\
\text { behavioral repertoire }\end{gathered}$

Figure 1: Illustration of ABC contingency.

pendent variables are called contingencies (Baum, 1994; Michael, 2000; Skinner, 1972; Whaler \& Fox, 1981). Figure 1 is a simplified illustration of the most basic behavioural unit of analysis, the three-term contingency, in which A stands for antecedent events that set the occasion for behaviour (B) to be emitted. The future probability of $B$ depends on consequent events $(C)$. $C$ either leads to an increase in the future probability of $\mathrm{B}$, in which case the term reinforcer is used; or $\mathrm{C}$ leads to a decrease in the future probability of $\mathrm{B}$, the term punisher is used.

In lay language, contingencies can be understood as the circumstances that influence or shape the behaviour of individuals or groups across the lifespan (Dillenburger \& Keenan, 2005). Explanations for behaviour are derived from a detailed analysis of how contingencies affect behaviour (Hanley, Iwata, \& McCord, 2003).

In fact, behavioural gerontology has been around for some time and has its own special interest group in the Association for Behavior Analysis. Although initially focusing on behavior problems in older residents of institutional settings, over 20 years ago Burgio and Burgio (1986) called for more behavioural gerontology research in community settings, especially given that $95 \%$ of individuals aged over 65 years of age live in the community. They suggested that behavior analysts should focus on teaching self-management skills to the elderly and training caregivers in behavior management skills. In a recent review of behavioural gerontology in the past 25 years, Buchanan, Husfeldt, Berg, \& Houlihan (2008) found that the elderly were still largely neglected by behavior analysts, with only about four published articles per year, one third of which concentrated on participants with cognitive impairments. However, the behaviour analytic view of aging has been applied to enjoying old age generally (Skinner \& Vaughan, 1997), teaching new skills to an 84-year old blind person (Dillenburger, Godina, \& Burton, 1997), and expanding behavioural repertoires of older residents of care homes (Gallagher \& Keenan, 2000a; 2000b).

The need for more behavior analytic work in aging was captured by Baron, Myerson and Hale (1988) who summed up the anti-discriminatory nature of behavioural thinking: "... [ $\mathrm{t}$ ] he power of conditioning variables provides a basis 


\section{DILLENBURGER \& MCKERR}

for questioning the pessimistic view that changes in the elderly are exclusively a biological matter. From a conditioning standpoint, the environments to which older adults are exposed (or to which they expose themselves) are not especially conductive to the acquisition and maintenance of competent behaviors" (p. 164).

The study reported here explored contingencies to which older people who care for their sons or daughters with disabilities are exposed and describes some of the behavioural patterns that evolve.

\section{ETHICAL APPROVAL}

Ethical approval for this study was granted through Research Ethics Committee, Queen's University of Belfast.

\section{PARTICIPANTS}

A non-representative purposive sample of 29 parents and carers (20 mothers, 8 fathers, 1 sister) who cared for a total of 27 adults with disabilities (15 sons, 11 daughters, and one sister) was recruited for this study. The average age of participants was 65.17 years (range 47-84 years). The average age of dependents was 33.48 years (range, 12-59 years). All participants lived in Northern Ireland.

\section{RESEARCH TOOLS}

A flexible and open-ended interview schedule was designed for the purpose of this study to encourage personally salient descriptions of richness and depth. The interview schedule was modelled on similar tools used in previous studies, such as the Carers' Assessment of Difficulties Index (CADI) and Carers' Assessment of Managing Index (CAMI) (Llewellyn et al., 2002). Questions addressed demographics of carer and dependent, circumstances of caring, positives and challenges, level of support from family, friends and social services, futures planning, and advice to others. The interview stance was curious and facilitative rather than challenging and interrogative.

In addition, the General Health Questionnaire (GHQ-12; Goldberg, McDowell, \& Newell, 1996) was used as a validated measure of psychological health. The GHQ-12 is used widely as indicator of psychiatric disturbance. It is scored on the standard binary scale. It has a maximum score of 12 and a threshold score of 4, at which respondents are classified as cases or non-cases. Scoring over 4 , and thus being classified as case, means that the respondent is likely suffering levels of tension, anxiety, and depression that have an adverse effect on their physical and mental wellbeing. In these cases, full psychological assessment is recommended. 


\section{PARENTS CARING FOR ADULT SONS AND DAUGHTERS}

\section{Procedure}

Participants were recruited through charities and support groups that work with persons with disabilities and their families in Northern Ireland. Support groups were identified using Duffy's (2008) contacts and personal contacts and recommendations. Initial contact was made by telephone, and where a group agreed to participate, interview dates were arranged with individual participants.

Interviews lasting 45-60 minutes were held either in the premises of the support group or the family home (whichever was preferred by participants). Information sheets and consent forms were read and signed prior to interview. Interviews were tape recorded (where possible) and transcribed. The GHQ-12 was completed by each carer independently, or read out by the researchers, depending on the participants' preference.

17 participants were interviewed on their own ( 2 of them were carers of two sons/daughters), while 12 participants took part in couple interviews ( 2 couples caring for two sons/daughters; 4 couples caring for one son or daughter).

\section{Data Analysis}

Interpretative phenomenological analysis (IPA) was employed for data analysis (Smith, Jarman, \& Osborne, 1999). IPA is an inductive, bottom-up methodology in which experiential accounts can be related to wider theoretical contexts. As such, the experiential-relevance or adequacy of a given theory can be examined. In the present context the theoretical framework was provided by behavior analysis.

Interview transcripts were read and re-read by both authors independently and coded through a process of shifting back and forth from the statements of participants to the researchers' interpretation. Recurring themes were identified and grouped into super-ordinate themes that formed the basis of interpretation.

\section{RESULTS AND DISCUSSION}

Behaviour analysts are generally apprehensive when research relies on verbal reports alone (Keenan, 1997). This is a legitimate concern because, of course, the verbal account of an event is not the same as the event itself (Skinner, 1989). In addition, Kenneth Lloyd (1994a; 1994b) identified the problem with correspondence between verbal and non-verbal behaviours when he showed empirically that what is said does not always correspond with what is done, i.e., verbal predictions of behaviour do not always correspond with actual future behaviour, and retrospective verbal descriptions do not always correspond with past behaviours. Because of considerations like this, behaviour analysts usually 


\section{DILLENBURGER \& MCKERR}

prefer to rely on direct observations and inter-observer agreements for more discernable data.

Despite these reservations, however, verbal reports are an essential aspect of behaviour analytic work. For example, the behavioural interview is an integral part of functional assessment and analysis (O'Neill et al., 1997) and verbal ratings have been used to aide experimental analysis of behaviour (Kelly et al. 2005). Phenomenological accounts are considered important descriptions of contingencies (Hayes \& Brownstein, 1987; Leigland, 1992; Wann, 1964) and were used here to illustrate contingencies to which participants were exposed and which affect their behaviour and the behaviour of their sons and daughters with disabilities as well as their relationships to each other.

\section{Relationships and Behavioural Networks}

Using verbal accounts participants described the complex network of relationships between themselves as carers, those for whom they cared, and the outside world. Caring was a full-time job for $90 \%$ of the participants and included physical care in $86 \%$ of the cases.

You see when [name of son] was given to us, he was given to us as a normal child, then a year later I'm sitting in an office with a paediatrician and he's telling me we'll look after him 'til he's 5 , if he survives that. So, I mean, he's 40 years old now and 40 years is an awful long time! (father, aged 75)

The term relationship is commonly used as summary label (Grant \& Evans, 1994) for interrelated, intertwined, and/or interdependent behavioural patterns. Like two dancers, the behaviour of individuals in relationships is shaped into specific behavioural repertoires. While some behavioural repertoires appear frequently, others are emitted at low rates. In other words, behaviours can be part of a repertoire even if they only occur once or twice a year, e.g., blowing out candles on a birthday cake.

These ever changing relationship patterns were reported by participants. Although care arrangements had changed over the years in $69 \%$ of the cases, $79 \%$ of the participants did not have an official care plan for their son/daughter with disabilities. This means that only $21 \%$ of the participants had adequate individual care plans, despite the fact that in the UK, local agencies were expected to have introduced Person Centred Planning for all individuals who were moving from children's to adult services by 2003 (White Paper, 2001). 66\% of the participants had discussed necessary changes with social services and $36 \%$ did not receive help or had to fight for help. 


\section{PARENTS CARING FOR ADULT SONS AND DAUGHTERS}

Coping with [name of daughter] as she and I mature is becoming more difficult... [name of daughter] is now more difficult to occupy. I find it difficult to find things that she likes to do and are age appropriate. [name of daughter] likes to go on swings and slides in the play park but the parents of other children do not always approve of having an adult play along side their children. When [name of daughter] was younger the general public were more understanding and sympathetic if she pushed past someone but this is no longer the case. I am also finding it more difficult to "keep up" with [name of daughter]... not as fit as I used to be. (mother, aged 62)

In many cases, carers described their own behavioural repertoires as just as dependent on those for whom they cared as the latter was on the former. This was the case in particular for emotional and social support after bereavement, for practical support with other disabled siblings, or when carers were unwell.

How would I describe it... is he a pain [laughing]? To me he's a joy and a pain all wrapped in to one... I look at him and think he's marvellous. I admire him, for where he is, how he is, and what he's done, and obviously, there's unconditional love... I don't feel him a burden any more... (mother, aged 60)

Most participants (79\%) enjoyed spending time and going out with their sons and daughters with disabilities. Interestingly, mutual dependency had little to do with actual levels of impairment. In fact, even severely impaired offspring provided support for carer behaviour, although obviously the level of practical help varied.

Oh, he's my best friend now I suppose, well that's not... I can't discuss things with him but he is my... he is just... well he's the one person in my life at the moment, the important person. Which is why I'll have to be very unselfish, when hopefully the social worker does find a suitable place, even for a trial period, to let him go. (mother, aged 79)

Figure 2 is a simplified illustration of mutually interdependent repertoires that develop when consequences for one behaviour become antecedents for another. Of course, relationships are not unidirectional and do not develop in a vacuum. Phenomenological accounts given by participants showed that relationships between carers, dependents, and their families constituted an interwoven network of behavioural repertoires that constantly adapted to circumstances.

They [other offspring] would always have been willing to watch [name of son] when I wanted them too, and they would have gladly. Brothers and sisters and their families and my own children would have watched him, no bother but I didn't... If I would have been getting the family to watch him, it would have been for a few hours, if we were going out at night or for a day... But when it came to overnight I would have used 


\title{
DILLENBURGER \& MCKERR
}

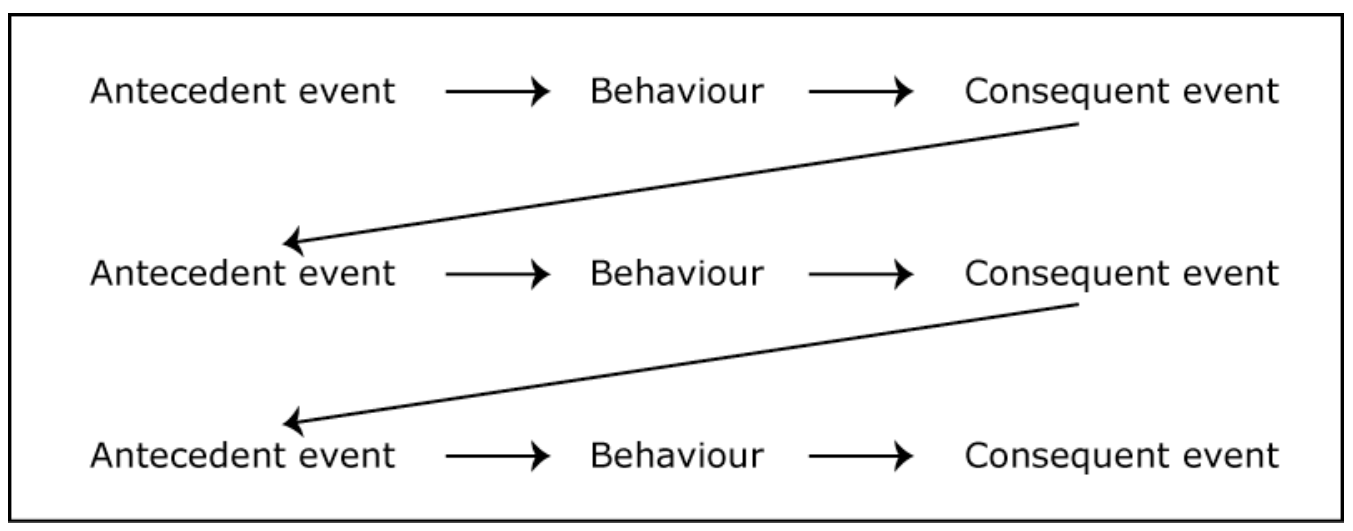

Figure 2: Illustration of mutually dependent behavioural repertoires.

\begin{abstract}
respite because [name of son]'s behaviour when he was younger would have been atrocious... absolutely. From the day and hour he started walking until he was in his teens he was horrendous to work with. The families wouldn't have kept him in a routine. They'd have spoiled him and when you picked him up you'd have been set back about 2 years! So, that was my main reason, not that they wouldn't have kept him but he needed the routine and he needed to be kept in the routine. He was crazy, he's a big gentle giant now but then he wouldn't have gone round you. There were days when I had two or three windows missing in the house. (mother, aged 60)
\end{abstract}

Two-thirds of the participants $(67 \%)$ relied on informal family arrangements in case the main carer fell ill; in $48 \%$ of cases there were no adequate substitute care arrangements. Only $14 \%$ of participants received help from friends or neighbours and $31 \%$ did not have any family support. Figure 3 illustrates the network of multiple relationships within families (adapted from Moynahan, 2001).

First, the couple dyad develops. Behavioural repertoires of each partner differ and the mutual relationship that develops is complex, unique, and includes a new range of repertoires, such as being each other's best friend, lover, confidant, advisor, husband, wife, etc. When a child arrives, additional relationships develop in the triad. Importantly, these relationships change over time as the needs of each individual changes; for example, the relationships between mother/father and newborn differ substantially to those of the same mother/father when the baby grows to be a toddler, school child, adolescent, and eventually, adult. The birth of a child does not only add to the complexity of the network of relationships, it also changes the characteristics of previously existing relationships and, of course, these changes are reciprocal. Obviously, where more than one child joins the family unit the complexity of the relationship network increases. 
PARENTS CARING FOR ADULT SONS AND DAUGHTERS

Reciprocal relationships between individual/husband and individual/wife:

Individual (husband) $\longleftrightarrow$ Individual (wife)

Reciprocal relationships between father, mother, and child:

Individual (husband/father)
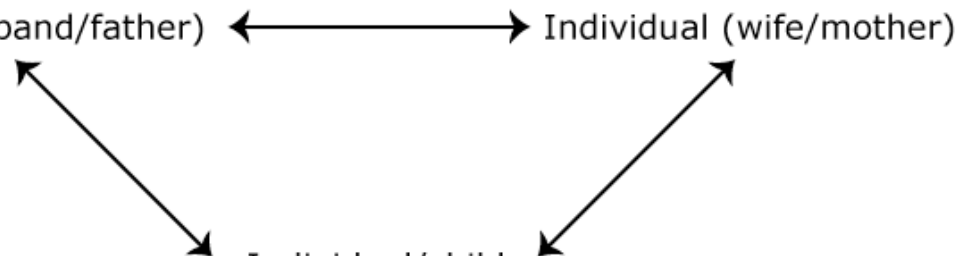

Individual/child



Network of reciprocal relationships between father, mother, and child:

Individual (husband/father) $\longleftrightarrow$ Individual (wife/mother)

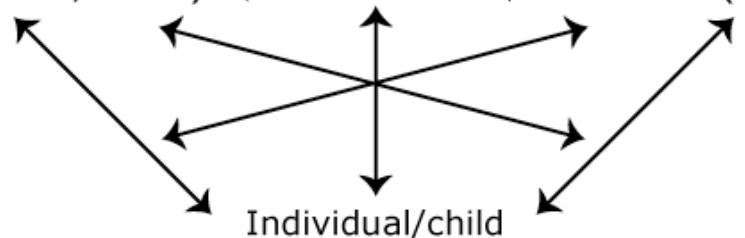

Figure 3: Illustration of family relationships.

The relationship with [name], my husband?... och, its excellent. He's very easy going, God love him... you know what pressure you're under. When [name of husband] was working I'd have been a 24-hour carer except at weekends but I never... whatever happened with [name of son] during the day was over, I never said... he would say how did things go and I'd say "Oh grand," though he might have seen there was two windows boarded up... So he knew everything wasn't grand but there was no point me saying "Oh wait "til I tell you the day I had today. I done this and he done that" and I hadn't the energy to go over it again anyway. Anyway, he never really showed that bad behaviour to his daddy. So by the time I twigged this on, he had me wrapped round his 


\section{DILLENBURGER \& MCKERR}

wee finger. There was no point in complaining to [name of husband], because he was already well-behaved... I was the problem and I had to teach him to behave when I'm there. I would have given [name of husband] an outline after [name of son] went to bed but I would never have got [name of husband] to say anything to him because the issue wasn't his behaviour with [name of husband], it was his behaviour when I'm with him... (mother, aged 60)

Figure 4 illustrates what happens when both parents have passed away. The offspring usually maintains some kind of uni-directional relationship with the deceased by thinking about them and missing them (Dillenburger \& Keenan, 2005), however, if there were no other support networks, the individual with disabilities would be on their own and inevitably in a crisis situation.

Difficult at the moment, was better in the past, a lot has changed since my husband died. (mother, aged 47)

Most of the participants (76\%) stated that their own health was good or fair, despite suffering from various health problems, yet most of the participants (72\%) had not made long-term plans for the future care of their sons or daughters with disabilities.

It was dreadful... I lay out in the hall and I couldn't get up... I think [name of son] was upstairs or something... eventually I managed to get to my feet and I got a friend... not that day, the next day, I wasn't able to get out of bed the pain was excruciating and she took me to the doctor and I got painkillers and then it was very bad and a week later I had to go down again and got stronger pain killers and I was just trying to manage and that's when I was very glad of his helper coming in. He was more than good, for he turned back my bed for me as well as [name of son]'s you know. (mother, aged 70)

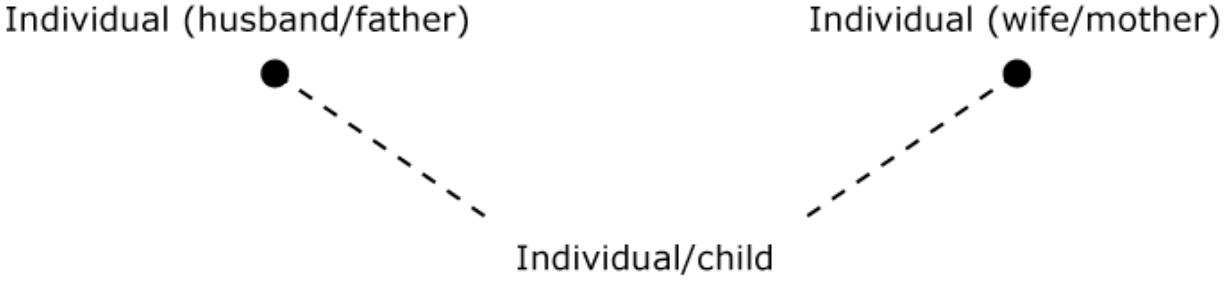

Figure 4: Illustration of lack of relationships when parents pass away. 


\section{PARENTS CARING FOR ADULT SONS AND DAUGHTERS}

Fortunately, family relationships commonly do not develop in a vacuum and other social relationships add to the complexity of the network, e.g., through school, work, leisure, or neighbourhood.

My neighbours were a great help, and my mother and father, but of course they're dead now too... They'd have held onto him for a couple of hours while we got sorted out... Our neighbour was a joiner and it got that when he heard glass breaking, [name of husband] would have been at work..., if [name of neighbour] heard glass breaking, he just brought hammer and nails with him, because he knew I was looking something boarded up. So, they were really good... The man at the back had that big garden and he gave him the freedom of it. He had only grass in it, you know, and it gave him great freedom because he couldn't have gone out the front. (mother, aged 60)

However, where only minimal social support was available during the lifetime of the parents, there will be a severe lack of support for a child or adult with disabilities once parents are unable to care or have passed away. Confirming earlier studies of widows of the Troubles (Dillenburger, 1992; Dillenburger \& Keenan, 1994/2001), those with inadequate networks of support experienced isolation, loneliness, physical and mental health problems, and heightened stress levels.

\section{Carers' Psychological Health}

The average GHQ-12 score for 26 participants was 3.61 (data missing for 3 participants); 35\% of the participants scored over 4, the threshold at which Goldberg et al. (1996) recommend further psychological assessment. A recent large-scale study in the same locality resulted in $17 \%$ of the general population scoring over the threshold of 4 (ARK, 2006). As such, participants in this study were more than twice as likely to experience psychological ill-health than the general population.

A functional behavioural analysis identifies causes of stress as either a deficit of skills or an excess of task demands (Dillenburger, 2000). Phenomenological findings reported here indicated that by-and-large carers were highly skilled in dealing with the physical and social needs of their sons and daughters, at times more so than professional care staff. Skills had developed over many years, were flexible, and generally well adapted to evolving circumstances.

It was done by the lassie... the domiciliary care worker who knows [name of daughter], for years... that was wheeked out in December and that was four hours a week... Now I want to state that [name of daughter] is NG feeding... fed with a naso-gastric tube... we were just told to get on with it! We took her out of hospital, about 5 years ago... and that's the problem, apparently the domiciliary worker cannot be trained to do it, 


\section{DILLENBURGER \& MCKERR}

although she had been doing it for three and a half years, you know, then all of a sudden the rules changed, and the agency said she couldn't do it any more... that's where [name of solicitor] comes into it, she's talking about the Human Rights Commission... We have given her our authority... official authority... to do this on our behalf... She knows how to go about it, we didn't know, we had a meeting with people from the agency in January... there's been nothing done since... just talking and talking, then [name of solicitor] has come on board, since then... she's getting answers anyway... she knows how to write the letters... whether it's the ones she wants or not... If it's not the ones she wants, she'll keep on... Well, she knew what to do and we didn't. She was a solicitor herself, plus she has a son with learning disabilities... We're very pleased that she's on board... that keeps us going... if we had nothing... It's great to talk to someone who knows what we're talking about, and what we're not getting... because she has got it all for her son... he's not on naso-gastric feeding or that, but she has everything set up for him, and they see him at weekends... so that's what we're looking for, for when we're gone... the district nurses won't touch her tube, if it comes out they won't touch it... we offered to put a clause in, to say that we wouldn't hold them responsible... but it doesn't matter... at the adult training centre there's one person... one person... who is allowed to look after [name of daughter]... and she goes on holiday this week, and a trained nurse has to come from [name of town]! If we were to get respite, she has to go into hospital, for nursing care... and she's not a hospital case... We wouldn't want the hospital situation... That's why we want this written down...

Stress therefore was not caused by skills deficit but by tasks becoming too demanding, at times due to policies that not allow for the necessary support. This was experienced on two levels. First, as carer's own physical strength and health decreased it was becoming increasingly difficult to complete caring tasks, especially if they involved physical lifting or social supervision. Second, ageing sons and daughters themselves developed increasing care and/or social needs. Respite care was hard to find even for short periods of time and worry about the future increased.

Greatest challenges for participants $(86 \%)$ were lack of respite, dealing with difficult behaviours, including physical aggression, and meeting sons/daughters' social needs.

The level of care that I can give is really nil... I can do less because of my own health problems, but I can still change a nappy, but I honestly couldn't dress her in the mornings. (mother aged 60).

Because of that, I'd say my share has gone up, but I can't change a nappy. It's a matter of [name of daughter ${ }^{1}$ 's dignity really, and we can't ask [name of daughter ${ }^{2}$ ] either to change [name of daughter ${ }^{1}$ 's nappy, not because she isn't willing to help, but she has learning disabilities and she would be a bit clumsy, you know it wouldn't be done right. (father, aged 66). 


\section{PARENTS CARING FOR ADULT SONS AND DAUGHTERS}

In addition, relatively high levels of skills deficit were reported with regard to sons and daughters with disabilities, e.g., adult sons or daughters were not able to dress themselves or look after their own personal hygiene. These and other basic life skills can be taught and learned through early behavioural intervention (Maurice, Green, \& Luce, 1996). Given the political unrest and severe lack of service provision in Northern Ireland (Darby \& Williamson, 1978) during their early childhood (average birth year 1976), these sons and daughters would not have benefited from recent advances in early behavioural interventions (Howard et al., 2005). As such, most of them displayed relatively high levels of helplessness (Seligman, 1972) and dependence on their parents/carers.

...there are things he doesn't like. He does not like taking a shower and there's a pushing and shoving match and the roars of him sometimes... and I'm always waiting 'til he breaks something. The shower equipment isn't that strong and [name of son] is a big, strong... and he refuses at times; "come on [name of son], shower" and he's"No!" (father, aged 70)

Early intensive behavioural intervention (EIBI; Howard et al, 2005) has been successfully applied to extend the skills levels and behavioural flexibility of children with disabilities, although its uptake has been slow in some countries (Keenan, 2004). Children with disabilities who benefit from EIBI have more behavioural choices and consequently are able to lead more independent adult lives than the sons and daughters in this study (McEachin, Smith, \& Lovaas, 1993).

\section{Behavioural Choice}

Participants in this study showed that while some of the current care demands were met, generally there was a severe lack of suitable services. This is not only a challenge for carers, but also a question of the rights of the sons and daughters with disability (Joint Committee on Human Rights, 2008). Given that the sample was comprised of sons and daughters who lived at home with their parents, one could ask to what extent the sons' or daughters' rights to make decisions as independent adults were considered. Most typically developing adults of their age would live independent lives away from the home in which they grew up. This was not an option for participating families because there was no suitable alternative accommodation where parents felt that their offspring would be cared for appropriately. Amongst other things, worry about inappropriate care or supervision or potential abuse was noted.

Well, I don't dwell on it... I don't dwell on that. We have carers as [name of husband] said, carers coming in every day, three times a day, it's an intrusion in your life. If you 


\section{DILLENBURGER \& MCKERR}

have your dinner at a certain time... so you're eating after 8 o'clock, or you're eating earlier when you don't really want to, so there's a lot of negative things, but again we can't get rid of the carers because there might come a time when we can't... we can change [name of son], if we have to, if it's a necessity and the carers aren't here... but my daughter, she would help as regards letting us out for a night or stuff like that but there's a lot of negative... more than positive.

In situations of high demand and low supply, conflict and stress are inevitable (Hursh, 1984). With the lack of suitable sheltered accommodation, participants felt they had to compete for access. The lack of suitable accommodation and support services should not be news to service providers. Numerous reports have pinpointed this deficit (e.g., Bamford, 2006; McConkey, 2004).

Those two things... day care and respite definitely... it would be [name of day care centre], she loves going over, she loves company... and the respite is a big help... it's a lady looks after [name of daughter] in her own house, you know, because we did try [name of daughter] in... some place. This is maybe 15-20 years ago when she was very young, for a weekend when we went to [name of town], and oh dear... she didn't like it at all. We phoned and we could hear someone screaming in the background... it wasn't [name of daughter], but for 6 months after that we couldn't get her to sleep. She was traumatised, she was definitely traumatised for months and months, it was awful and we said we'd never do that again, so they did look for a host family, a nice lady and gent who lived up in [name of town] but they've retired now, they're older than us... This lady's very nice, they have a wee bungalow... (father, aged 60)

It seems that while society relies on older parents and informal carers to take full caring responsibility, and thereby making substantial savings, the situation is unlikely to change. Inadvertently, the huge amount of high quality care given freely and willingly by the parents reinforces, or increases the future probability of inactivity of service providers (see Figure 1).

Lipsitt (2005) draws attention to the perils of ignoring behavioural science; "sometimes our vision for the future requires not a leap in faith but a scientific jump-start" (p. 203). A scientific jump-start is necessary to calculate future care and accommodation needs on the basis of the number of children born with impairments and the number of people who suffer impairments later in life. In this way, reasonably accurate predictions can be made and provision planned well in advance. The reality evidenced in this paper is that by-and-large these calculations are not followed by adequate action. Consequently older parents were expected to carry the full responsibility for care and futures planning against a backdrop of severe shortage of provision.

It's very sensitive to approach it really and the odd time you would say something the boys just don't want to hear... "Leave him alone, he'll be grand"... I went through a stage about four or five years ago... "What would happen to [name of son]?"; "Don't 


\section{PARENTS CARING FOR ADULT SONS AND DAUGHTERS}

you worry about him"; and "I need to make a will" and [name of son $\left.{ }^{1}\right]$ said "as far as that's concerned don't you worry about [name of son], [name of son] will be grand", but I feel it's awful. They might be landed with a situation... see he's away all the time. Say you were to make a will, when you're well you don't think, [name of son] is not capable of looking after anything on that level but I cannot bring myself to say where everything was... always in threes, and I can't bring myself to leave him out but including him... I can't see them managing on it because the boys would be looking after him and I wouldn't want them financially disadvantaged... and [name] is $83 \ldots$ but he would know the boys would look after [name of son]... [name of son ${ }^{1}$ ] is the kid who nearly reared him. I think, we should do it some of these days. Things can change very quickly... It worries me terribly, but the fact that he has two brothers is a great bonus for him... but to be realistic [name of son'] has two wee fellas of his own... but it's going to have to be their choice, but he wasn't very welcoming to the grandchildren... He loves them now... (mother, 75)

Necessary networks include extended family, friends, financial security, accommodation, statutory bodies, employment, and day care. Figure 5 illustrates the necessary network of social support.

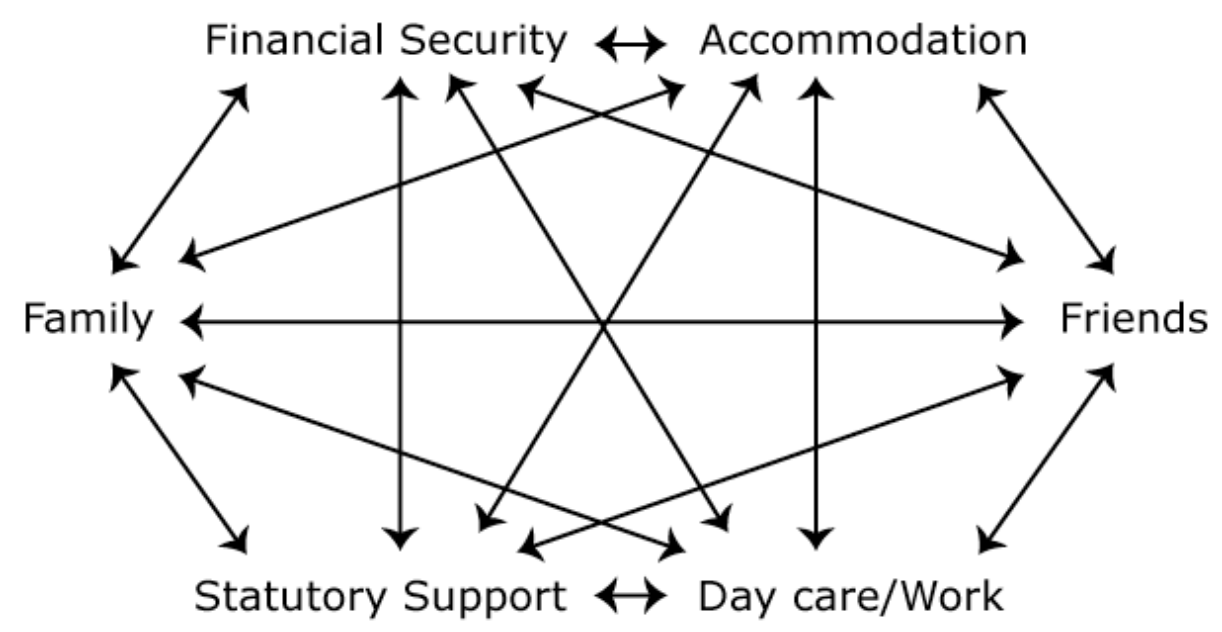

Figure 5: Illustration of necessary support network. 


\section{DILLENBURGER \& MCKERR}

...if I wasn't home for [name of daughter] coming home at 3.30, all I have to do is ring the bus or ring the school and say, would the bus driver leave her off at Auntie [name]'s this evening. Then they know on Thursdays to leave her down with the other friend. So, I have two others if needs be, but everybody you know, is busy. There's no point in saying, except they're paid for looking after someone, no-one does this any more. The extended family is over, everybody has their own homes, even if their mother or father needs looking after, they can't come... (mother, aged 80)

These mutual interrelated relationships cannot be built overnight or in a crisis situation, they require planning and long-term partnership between all participants, including parents and sons and daughters with disabilities.

The only thing that is there is this... it's not... it's vague... that [name of daughter ${ }^{1}$ ] will take care of [name of son] if anything was to happen. She's got the room and that, up there, but initially, [name of daughter ${ }^{2}$ ] would have been saying "That's not fair" and I'd have said "Hey, they're family and the family will take responsibility when we're not there." I'm softening up on that now you realise they have their own family... (mother, aged 60)

In cases where strong support networks were established during the lifetime of the parents, sons and daughters with disabilities will be caught securely in a safety net of support when parents are no longer available (Figure 6).

...4 or 5 years ago I did take the step of creating a circle of support... I learned for the first time, instead of bearing it all myself, to go out and say, "Can you help." So my sister, and sister-in-law and Nanny became what we call ... and they're involved with [name of son]'s care and if we want to find out what he's thinking, we would bat things off them... If we want to find out what [name of son]'s feeling, they would share. He has very close communication with all of them, so it doesn't just depend on me, but I did set that up... out of desperation... [mother, aged 60]

\section{CONCLUSION}

From a behaviour analytic perspective it is not the age of the person, but the function of the behaviour that counts (Dillenburger \& Keenan, 1997). This analysis leads to a new way of conceptualising human behaviour, because it concentrates attention on the environmental influences (i.e., antecedents and consequences) of behaviour, offers a life-span approach, is applicable crossculturally and cross-racially, and is open to individual differences. As such it offers a framework for meeting the challenges posed by this study, as Michael McGimpsey said after taking on the Health, Social Services and Public Safety portfolio in Northern Ireland in May 2007. "One of the greatest challenges I faced was how to reform and modernise our health and social care system so that it is truly fit for the twenty-first century" (McGimpsey, 2008, p.2). 


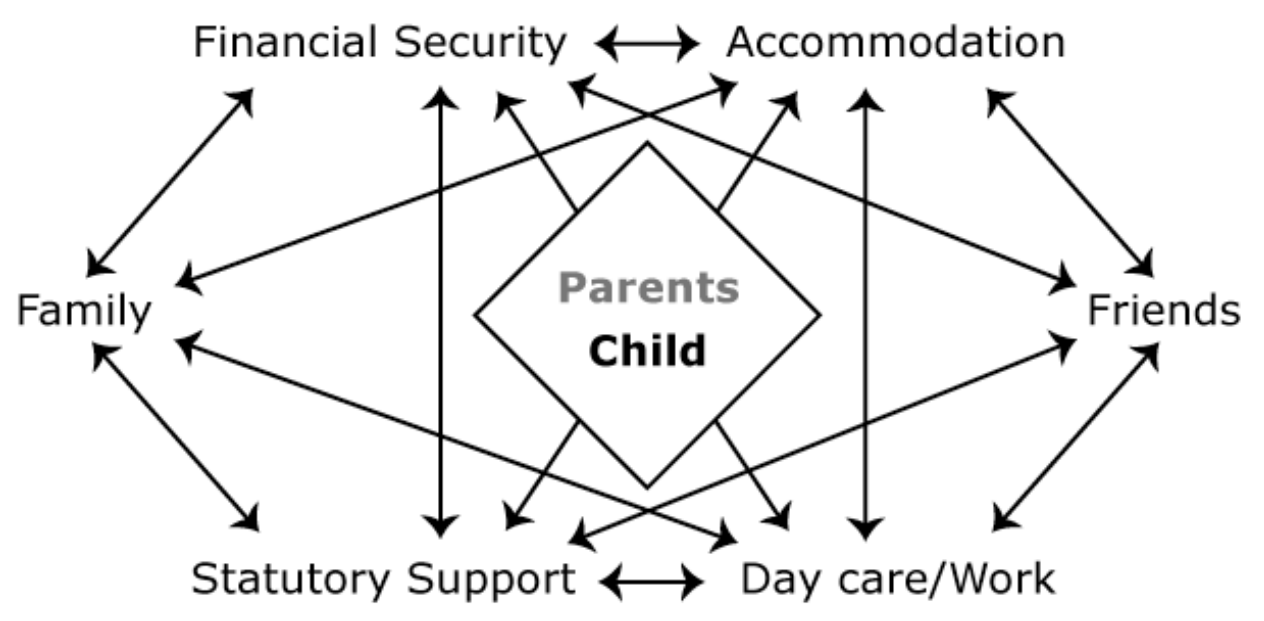

Figure 6: Illustration of parents/child at the centre of network of support.

The study reported here offers a pathway for reform and modernisation. It confirms the importance of early behavioural intervention for persons with disabilities (cf. Keenan et al., 2007) and points towards the need for early onset of future planning. In accord with the UN Convention on the Rights of Persons with Disabilities, the Obama administration in the US promised to "First, provide Americans with disabilities with the educational opportunities they need to succeed by funding the Individuals with Disabilities Education Act, supporting early intervention for children with disabilities and universal screening, improving college opportunities for high school graduates with disabilities, and making college more affordable" [emphasis in original text] (The White House, 2009b). In addition, the new administration explicitly recognised the skills of older people. "Retired Americans have a wide range of skills and knowledge to contribute to local and national public service efforts." (The White House, 2009a). The study reported here underpins these aims as necessary, timely, and internationally relevant. 


\section{DILLENBURGER \& MCKERR}

\section{REFERENCES}

Access Research Knowledge Northern Ireland (ARK, 2006). Northern Ireland Life and Times Survey. Retrieved May 22, 2008 from http://www.ark.ac.uk/nilt/2006/Healthcare/GHQ12CASE.html

Bamford, D. (2006). The Bamford review of mental health and learning disability (Northern Ireland). Retrieved December 3, 2007 from $\mathrm{http}: / /$ www.rmhldni.gov.uk/asd_report_may06.pdf

Baron, A., Myerson, J., \& Hale, S. (1988). An integrated analysis of the structure and function of behavior: Ageing and the cost of divided attention. In G. Davey and C. Cullen (Eds.), Human operant conditioning and behavior modification (pp. 139-166). Chichester: John Wiley and Sons.

Buchanan, J., Husfeldt, J., Berg, T., \& Houlihan, D. (2008). Publication trends in behavioral gerontology in the past 25 years: Are the elderly still an understudied population in behavioral research? Behavioral Interventions, 23, 65-74. http://dx.doi.org/10.1002/bin.254

Buckner, L. \& Yeandle, S. (2007). Valuing carers: Calculating the value of unpaid care. London: Carers UK.

Burgio, L.D. \& Burgio, K.L. (1986). Behavioral gerontology: Application of behavioral methods to the problems of older adults. Journal of Applied Behavior Analysis, 19, 321-328. http://dx.doi.org/10.1901/jaba.1986.19-321

Cambridge Centre for Behavioral Studies (2009). Retrieved January 25, 2009 from $\mathrm{http}: / / \mathrm{www} \cdot$ behavior.org

Dahlberg, L., Demack, S. \& Bambra, C. (2007). Age and gender of informal carers: A populationbased study in the UK. Health \& Social Care in the Community, 5, 439-445. http://dx.doi.org/10.1111/j.1365-2524.2007.00702.x

Darby, J. \& Williamson, A. (Eds.) (1978). Violence and the social services in Northern Ireland. Heinemann: London.

Dillenburger, K. (1992). Violent bereavement: Widows in Northern Ireland. Aldershot: Avebury.

Dillenburger, K., Godina, L. \& Burton M. (1997). Behavioural social work training: A pilot study. Research on Social Work Practice. 1, 70-78.

Dillenburger, K. (2000). Functional assessment and analysis. In M. Davies (Ed.) Encyclopaedia of Social Work. Oxford: Blackwell Publishers.

Dillenburger, K. \& Keenan, M. (1994/2001). Bereavement: A behavioural process. European Journal of Behaviour Analysis, 2, 129-138. First published in Irish Journal of Psychology, 15, 524-539. Reprinted with peer commentaries.

Dillenburger, K. \& Keenan, M. (1997). Human development: A question of structure and function. In K. Dillenburger, M. O’Reilly, \& M. Keenan (Eds.). Advances in Behaviour Analysis (pp. 3-22). Dublin: University College Dublin Press.

Dillenburger, K. \& Keenan, M. (2005) Bereavement: A D.I.S.C. analysis. Behavior and Social Issues, 14, 92-112. http://dx.doi.org/10.5210/bsi.v14i2.333

Duffy, J. (2008). Looking out from the middle: User involvement in health and social care in Northern Ireland. London, UK: Social Care Institute for Excellence.

Erikson, E. (1963). Childhood and society (2nd ed.). New York: Norton.

Gallagher, S. M., \& Keenan, M. (2000a). Extending high rates of meaningful interaction among the elderly in residential care through participation in a specifically designed activity.

Behavioral Interventions, 15, 113-119. http://dx.doi.org/10.1002/(SICI)1099-078X(200004/06)15:2<113::AID-BIN46>3.0.CO;2-Y

Gallagher, S. M., \& Keenan, M. (2000b). Independent use of activity materials by the elderly in a residential setting. Journal of Applied Behavior Analysis, 33, 325-328. http://dx.doi.org/10.1901/jaba.2000.33-325 


\section{PARENTS CARING FOR ADULT SONS AND DAUGHTERS}

Gallagher, S. M., \& Keenan, M. (2006). Gerontology and applied social technology. European Journal of Behaviour Analysis, 7, 77-86.

Goldberg, D., McDowell, I., \& Newell, C. (1996). Measuring health: A guide to rating scales and questionnaires (2nd ed.). New York: Oxford University Press.

Grant, L., \& Evans, A. (1994). Principles of behavior analysis. New York: HarperCollins College Publishers.

Hayes, S. C., \& Brownstein, A. (1987). Mentalism, private events, and scientific explanation: A defense of B. F. Skinner's view. In S. Modgil \& C. Modgil (Eds.), B. F. Skinner: Consensus and controversy. New York: Falmer Press.

Howard, J. S., Sparkman, C. R, Cohen, H. G., Green, G., \& Stanislaw, H. (2005). A comparison of intensive behavior analytic and eclectic treatments for young children with autism. Research in Developmental Disabilities, 26, 359-383. http://dx.doi.org/10.1016/j.ridd.2004.09.005

Hursh, S.R. (1984). Behavioral economics. Journal of Experimental Analysis of Behavior, 42, 435-452. http://dx.doi.org/10.1901/jeab.1984.42-435

Joint Committee on Human Rights (2008). A life like any other? Human rights of adults with learning disabilities. London: House of Lords House of Commons

Keenan, M. (1997). Teaching about private events in the classroom. Behavior \& Social Issues, 6 , 75-84.

Keenan, M. (2004). Autism in N. Ireland: The tragedy and the shame. The Psychologist, 17, 7275.

Keenan, M., Dillenburger, K., Doherty, A., Byrne, J., \& Gallagher, S. (2007). Meeting the needs of families living with children diagnosed with autism spectrum disorder (Final Report). Coleraine, NI: University of Ulster. Retrieved February 27, 2009 from http://www.peatni.com

Kelly, T. H., Hienz, R. D., Zarcone, T. J., Wurster, R. M., \& Brady, J. V. (2005). Crewmember performance before, during, and after spaceflight. Journal of Experimental Analysis, 84, 227241. http://dx.doi.org/10.1901/jeab.2005.77-04

Leigland, S. (1992). Radical behaviorism: Willard Day on psychology and philosophy. Reno, NV: Context Press.

Lipsitt, L.P. (2005). Ignoring behavioral science: Practices and perils. In D. B. Pillemer \& S. H. White (Eds.), Developmental psychology and social change (pp. 203-221). Cambridge: Cambridge University Press.

Llewellyn, G., Gething, L., Kendig, H., \& Cant, R. (2003). Invisible carers facing an uncertain future. Sydney, AU: Faculty of Health Sciences, University of Sydney.

Lloyd, K. E. (1994a). Do as I say, not as I do. The Behavior Analyst, 17, 131-139.

Lloyd, K. E. (1994b). Addenda. The Behavior Analyst, 17, 141-144.

Maurice, C., Green, G., \& Luce, S. (1996) Behavioural intervention for young children with autism. Austin, Texas: Pro-Ed.

McConkey, R. (2004). Pressures, possibilities and proposals: Northern Ireland review of day services for people with learning disabilities. Belfast: Eastern Health and Social Services Board.

McGimpsey, M. (2008). Proposals for health and social care reform: Consultation report. Belfast: Modernisation Directorate Department of Health, Social Services and Public Safety.

Michael, J. (2000). Implications and refinements of the establishing operation concept. Journal of Applied Behavior Analysis, 33, 401-410.

Minnes, P. \& Woodford, L. (2005). Well-being in aging parents caring for an adult with a developmental disability. Journal on Developmental Disabilities, 11, 48-66. 


\section{DILLENBURGER \& MCKERR}

Moynahan, L. (2001). Relatio ergo sum-a spontaneous commentary upon Dillenburger and Keenan. European Journal of Behaviour Analysis, 2, 162-174.

Obama, B. (April 11, 2008). Retrieved February 25, 2009 from http://www.whitehouse.gov/agenda/

O’Neill, R. E., Horner, R. H., Albin, R. W., Sprague, J. R., Storey, K., \& Newton, J. S. (Eds.) (1997). Functional assessment and program development for problem behavior: A practical handbook. London: Brooks/Cole Publishing Company.

Robinson, C. \& Williams, V. (2002). Carers of people with learning disabilities, and their experience of the 1995 Carers Act. British Journal of Social Work, 32, 169-183. http://dx.doi.org/10.1093/bjsw/32.2.169

Scott, D. \& Donnelly, M. (2008). Buying time for better decision-making: The impact of home based rehabilitation on frail older people. The Open Rehabilitation Journal, 1, 5-14. http://dx.doi.org/10.2174/1874943700801010005

Seligman, M.E.P. (1972). Learned helplessness. Annual Review of Medicine, 23, 407-412. http://dx.doi.org/10.1146/annurev.me.23.020172.002203

Skinner, B. F. (1989). Recent issues in the analysis of behavior. Ohio: Merrill Publishing Co.

Skinner, B. F. \& Vaughan, M. E. (1997). Enjoy old age: A practical guide. New York: W. W. Norton \& Company.

Smith, J., Jarman, M. \& Osborne, M. (1999). Doing interpretative phenomenological analysis. In M. Murray \& K. Chamberlain (Eds.), Qualitative Health Psychology. London: Sage.

The White House (2009a). The agenda: Seniors \& social security. Retrieved February 25, 2009 from http://www.whitehouse.gov/agenda/seniors and social security/

The White House (2009b). The agenda: Disability. Retrieved February 25, 2009 from http://www.whitehouse.gov/agenda/disabilities/

Walker, C. \& Walker, A. (1998) Uncertain futures: People with learning difficulties and their ageing family carers, Brighton: Pavilion Publishing/Joseph Rowntree Foundation.

Wann, T. W. (1964) (Ed.). Behaviorism and phenomenology: Contrasting bases for modern psychology. Chicago: University of Chicago Press.

White Paper (2001). Valuing people: A new strategy for learning disability in the 21st Century. Retrieved February 5, 2009 from http://www.dh.gov.uk/ 